\title{
Combined Economic Emission Dispatch using Evolutionary Programming Technique
}

\author{
K. Senthil M.E. \\ Lecturer, Power Systems \\ Department of Electrical \& Electronics Engineering, \\ St.Joseph College of Engineering \& Technology, \\ Dar Es Salaam, Tanzania.
}

\begin{abstract}
In recent years increasing of thermal power plants air pollution and concentration of carbon dioxide emission leads to the global warming. This paper solves the economic dispatch problem includes the dispatch of systems to the minimize carbon dioxide emissions, as well as to achieve the minimum fuel cost. This paper proposed a lambda based approach for solving the Combined Economic and Emission Dispatch (CEED) problem using Evolutionary programming (EP) method considering the power limits. The CEED is to minimize both the operating fuel cost and emission level simultaneously while satisfying the load demand and operational constraints. The sample test system of three and six generator system solves the CEED problem for various load demands. The numerical results have shown the performance and applicability of the proposed method.
\end{abstract}

\section{Keywords}

Economic Dispatch, Combined Economic Emission Dispatch, Carbon dioxide Emission, Evolutionary Programming Technique and Global Warming

\section{INTRODUCTION}

Electric utility system is interconnected to achieve the benefits of minimum production cost, maximum reliability and better operating conditions. The economic scheduling is the on-line economic dispatch, wherein it is required to distribute the load among the generating units which are actually paralleled with the system, in such a way as to minimize the total cost of generating. It is assumed that some flexibility exists in adjusting the power delivered by each generator. Of course, if the peak demand is so large that all the available generation capacity must be used, there are no options. But usually the total is less than the available generation capacity and there are many possible ways of assigning individual generation powers. It is important to emphasize that the solution approach will consider the problem of minimizing the production cost in real time under the assumption that the generators which are on-line or committed at a given moment are specified along with their generation limits. The optimizing concerns this particular set of generators. In the case of economic load dispatch the generations are not fixed, they are allowed to take values within certain limit so as to meet particular load demand with

Minimum generation cost. Thus, the economic load dispatch solution can be viewed as the optimal solution in a large number of possible programming solution in the sense that it corresponding to the minimum cost of generation. The economic load dispatch problem pertains to the optimum generation scheduling of available generating units in a power system to minimize the cost of generation subject to system constraints. Due to strict governmental regulations on environment protection, the conventional operation at absolute minimum fuel cost cannot be the only basis for dispatching electric power. There is a need from society for adequate and secure electricity at the cheapest possible price with minimum levels of pollution. It is compulsory for electric utilities to reduce pollution level by reducing $\mathrm{CO}, \mathrm{CO} 2, \mathrm{SO} 2$ and $\mathrm{NOx}$. Various methods available for reducing emissions are switching to low sulphur content coal, installing post-combustion cleaning system, allocation of generation to each generator unit with the objective to minimum emission dispatch. But even though the emission levels will not be reduced. So this paper uses an EP computational approach to reduce the total system operating cost \& emission levels.

\section{ECONOMIC THERMAL POWER DISPATCH PROBLEM FORMULATION}

Economic dispatch problem is one of the most important problems in electric power system operation. Large scale system, the problem is more complex and difficult to find out optimal solution because it is nonlinear function and it contains number of local optimal. The basic main purpose for solving economic dispatch problem is to schedule the outputs of the generating units so as to meet the system load at least fuel cost under various system and operating constraints.

\subsection{Economic Dispatch Problem}

The objective of solving the economic dispatch problem in electric power system is to determine the generation levels for all on-line units which minimize the total fuel cost and minimizing the emission level of the system, while satisfying a set of constraints. It can be formulated as follows:

The economic dispatch problem can be modeled by

Minimize $\mathrm{F}_{\mathrm{T}}=\sum_{i \varepsilon \Omega} F_{i}\left(P_{i}\right) \quad \mathrm{Rs} / \mathrm{hr}$

Where

$\mathrm{F}_{\mathrm{T}}$ is the total fuel cost

$F_{i}\left(P_{i}\right)$ is the fuel cost of generating unit i 


\subsection{Fuel Cost Function}

The fuel cost function of a generating unit is usually described by a quadratic function of power output $\mathrm{P} i$ as:

$$
F_{i}\left(P_{i}\right)=\mathrm{a}_{\mathrm{i}} \mathrm{P}_{\mathrm{i}}^{2}+\mathrm{b}_{\mathrm{i}} \mathrm{P}_{\mathrm{i}}+\mathrm{c}_{\mathrm{i}} \quad \mathrm{Rs} / \mathrm{hr}
$$

\section{Where}

$a_{i}, b_{i}$ and $c_{i}$ are the cost co-efficient of unit $i$

\subsection{Emission Equation}

The Emission equation of a generating unit is usually described by a quadratic function of power output $\mathrm{P} i$ as:

$$
E_{i}\left(P_{i}\right)=\mathrm{d}_{\mathrm{i}} \mathrm{P}_{\mathrm{i}}^{2}+\mathrm{e}_{\mathrm{i}} \mathrm{P}_{\mathrm{i}}+\mathrm{f}_{\mathrm{i}} \quad \mathrm{Kg} / \mathrm{hr}
$$

\section{Where}

$d_{i}$, ei and $f_{i}$ are the emission co-efficient of unit $i$

\subsection{Emission Constrained Cost Equation}

The Emission constrained cost equation can now be formulated as:

$$
\begin{aligned}
F_{i}^{\mid}\left(P_{i}\right)=\left(\mathrm{a}_{\mathrm{i}} \mathrm{P}_{\mathrm{i}}^{2}+\mathrm{b}_{\mathrm{i}} \mathrm{P}_{\mathrm{i}}+\mathrm{c}_{\mathrm{i}}\right)+ \\
\mathrm{h}_{\mathrm{i}}\left(\mathrm{d}_{\mathrm{i}} \mathrm{P}_{\mathrm{i}}^{2}+\mathrm{e}_{\mathrm{i}} \mathrm{P}_{\mathrm{i}}+\mathrm{f}_{\mathrm{i}}\right) \mathrm{Rs} / \mathrm{hr}
\end{aligned}
$$

\subsection{Formation of Penalty Factor}

$\mathrm{h}_{\mathrm{i}}=F_{i} \max / E_{i} \max$

$$
\begin{aligned}
& F_{i} \max =\mathrm{a}_{\mathrm{i}} \mathrm{P}_{\mathrm{i}}^{2} \max +\mathrm{b}_{\mathrm{i}} \mathrm{P}_{\mathrm{i}} \max +\mathrm{c}_{\mathrm{i}} \mathrm{Rs} / \mathrm{hr} \\
& E_{i} \max =\mathrm{d}_{\mathrm{i}} \mathrm{P}_{\mathrm{i}}^{2} \max +\mathrm{e}_{\mathrm{i}} \mathrm{P}_{\mathrm{i}} \max +\mathrm{f}_{\mathrm{i}} \quad \mathrm{Kg} / \mathrm{hr}
\end{aligned}
$$

\subsection{Power Balance Constraints}

The total generation must supply the demand

$$
\sum_{i \varepsilon \Omega}(P i)=\mathrm{P}_{\mathrm{D}}
$$

Where

$\mathrm{P}_{\mathrm{D}}$ is the load demand

\subsection{Generator Limit Constraints}

The power generation of unit ' $n$ ' should be between its minimum and maximum limits.

$$
\mathrm{P}_{\mathrm{n} \min } \leq \mathrm{P}_{\mathrm{n}} \leq \mathrm{P}_{\mathrm{n} \max }
$$

Where

$\mathrm{P}_{\mathrm{i} \text { min }}$ is the minimum generation limit of unit $\mathrm{i}$

$P_{i \max }$ is the maximum generation limit of unit $i$

\section{EVOLUTIONARY PROGRAMMING}

Evolutionary Programming [11] is a stochastic optimization strategy originally conceived by Lawrence J. Fogel in 1960. An initially random population of individuals (trial solutions) is created. Mutations are then applied to each individual to create new individuals. Mutations vary in the severity of their effect on the behavior of the individual. The new individuals are then compared in a "tournament" to select which should survive to form the new population. EP is similar to a genetic algorithm, but models only the behavioral linkage between parents and their offspring, rather than seeking to emulate specific genetic operators from nature such as the encoding of behavior in a genome and recombination by genetic crossover. EP is also similar to an evolution strategy (ES) although the two approaches developed independently. In EP, selection is by comparison with a randomly chosen set of other individuals whereas ES typically uses deterministic selection in which the worst individuals are purged from the population.Evolutionary algorithms, such as evolutionary programming (EP), evolution strategies (ES), genetic algorithms (GA), and genetic programming (GP), have attracted considerable interest as optimization heuristics during the past 10-15 years. Because of the exponential increase in computer power during the last decade, they are able to deal with real-world problems and new application domains are still arising. Although evolutionary algorithms are easy to implement, the underlying process is complicated and stochastic, depending on the fitness function and the free parameters controlling variation and selection. The analysis of these stochastic processes seems to be much more difficult than the analysis of randomized algorithms for special purpose.

\subsection{Motivation}

Evolutionary algorithms (EAs) are stochastic optimization methods that are based on principles derived from natural evolution. Mutation, recombination, and selection are iterated with the goal of driving a population of candidate solutions toward better and better regions of the search space. From a more general perspective, EAs are one instance of bio-inspired search heuristics. Other examples include Ant Colony Optimization (ACO) and Particle Swarm Optimization (PSO), where the search behaviors of ant colonies or insect swarms inspired a randomized search technique. Since the underlying ideas of bio-inspired search are easy to grasp and easy to apply, EAs and different bio-inspired search heuristics are widely used in many practical disciplines, mainly in computer science and engineering.It is a central goal of theoretical investigations of search heuristics to assist practitioners with the tasks of selecting and designing good strategy variants and operators. Due to the rapid pace at which new strategy variants and operators are being proposed, theoretical foundations of EAs and other bio-inspired search heuristics still lag behind practice. However, EA theory has gained much momentum over the last few years and has made numerous valuable contributions to the field of evolutionary computation. Much of this momentum is due to the Dagstuhl seminars on "Theory of Evolutionary Algorithms", which have been held biannually since 2000. We want to build on this success and continue to promote discussions between researchers in different areas of the theory of all kinds of bio-inspired search heuristics. The theory of EAs today consists of a wide range of different approaches. Runtime analysis, schema theory, analyses of the dynamics of EAs, and systematic empirical analysis consider different aspects of EA behavior. Moreover, they employ different methods and tools for attaining their goals, such as Markov chains, infinite 
population models, or ideas based on statistical mechanics or population dynamics. In the most recent seminar, more recent types of bio-inspired search heuristics were discussed. Results regarding the runtime have been generalized from EAs to ACO and PSO. Although the latter heuristics follow a different design principle than EAs, the theoretical analyses reveal surprising similarities in terms of the underlying stochastic process. Theoretical studies of EAs in continuous domain have recently evoked interest of people working in the field of classical numerical optimization. Although stochastic and deterministic optimization algorithms address optimization of different types of problems---mainly convex and smooth for deterministic algorithms and noisy, multimodal, irregular for stochastic algorithms---the focuses of both fields became closer and closer: on the one hand many hybridizations of stochastic search and gradient-based algorithms have been proposed, on the other hand, derivative-free optimization is now a wellestablished part of the research in the classical optimization community.

\subsection{Evolutionary Programming Algorithm}

i. An Initial population of $\mathrm{Np}$ parent vectors is considered as the trial solution

ii. From these parents offsprings are created by mutation, hence $\mathrm{Np}$ off springs are obtained

iii. By combining the parents and off springs, $2 \mathrm{~Np}$ solutions are obtained

iv. Through competition and selection, first $\mathrm{Np}$ optimal solutions are selected

v. The selected solutions are considered as parents for the next iteration

vi. After the required number of iterations, the best optimal solution is obtained

\section{SAMPLE TEST SYSTEM AND ITS RESULTS}

The power system optimization using EP technique solves the CEED. The cost coefficients and emission coefficients of three generator and six generator test system are show in Table 1 and Table 3 respectively. Table 2 shows the results of fuel cost, emission value, emission constrained fuel cost and execution time for the three generator test system. The load demand of the system is $400 \mathrm{MW}-700 \mathrm{MW}$. The simulation is carried out using the Mat Lab Software. The results shows that the combined economic emission dispatch of three and six generator system is solved using EP technique with minimum fuel cost and emission values. The table 4 shows the results of fuel cost, emission value and emission constrained fuel cost of the six generator test system. EP solves any non linear functions with minimum fuel cost and emission values. Many of the hybrid algorithms only help to improve the solution accuracy. But this proposed technique is Very well defined and the solution accuracy is excellent. The results show that EP can converge to near global minimum with less search account and it is high efficiency. Thus, it obtains the solution with high accuracy.

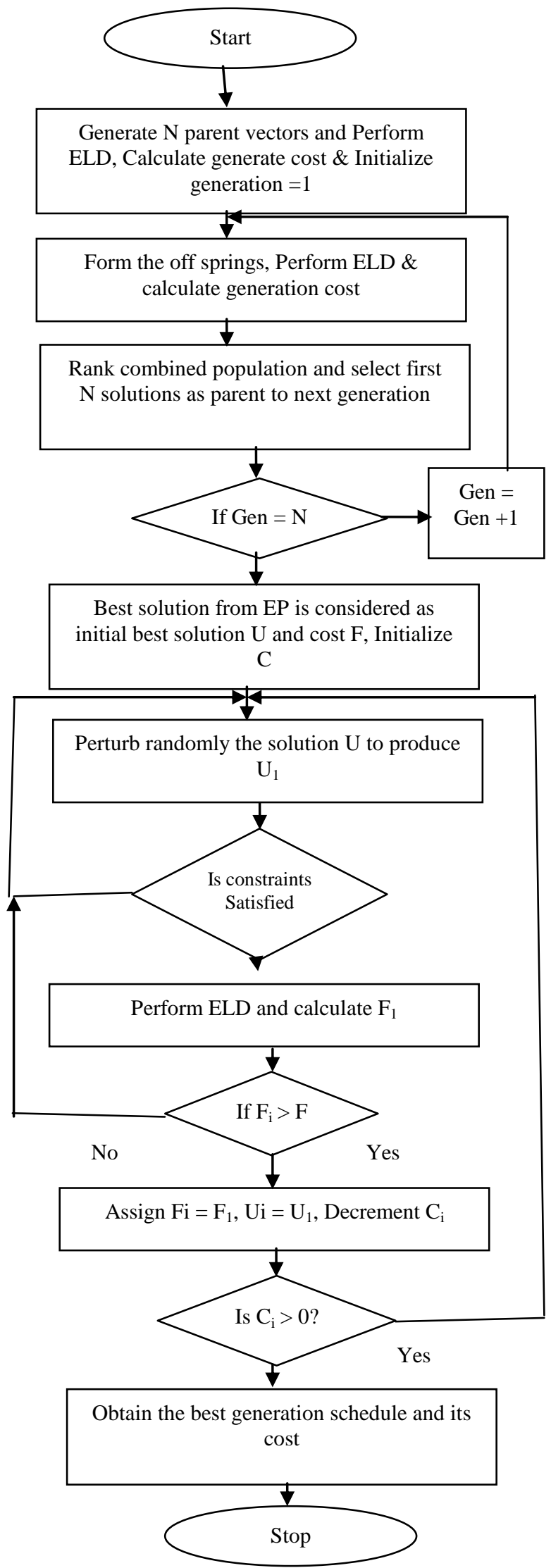

Figure 1. Flow Chart for CEED Using EP 
Table 1: Cost Coefficients and Emission Coefficients of Three Generator System

\begin{tabular}{ccccc}
\hline $\mathrm{a}_{\mathrm{i}}$ & $\mathrm{b}_{\mathrm{i}}$ & $\mathrm{c}_{\mathrm{i}}$ & $\mathrm{d}_{\mathrm{i}}$ & $\mathrm{e}_{\mathrm{i}}$ \\
\hline 0.03546 & 124.5311 & 0.00683 & -0.54551 & 40.2669 \\
0.02111 & 1658.5696 & 0.00461 & -0.5116 & 42.89553 \\
0.01799 & 1356.6592 & 0.00461 & -0.5116 & 42.89553 \\
\hline
\end{tabular}

Table 2: Three Generator Systems Fuel Cost, Emission Value and Emission Constrained Fuel Cost for Various Load Demand

\begin{tabular}{|c|c|c|c|c|c|c|c|}
\hline $\begin{array}{c}\text { Power } \\
\text { Demand } \\
\text { MW }\end{array}$ & MW & MW & MW & $\begin{array}{c}\text { Fuel cost } \\
\text { Rs/hr }\end{array}$ & $\begin{array}{c}\text { Emission } \\
\mathrm{Kg} / \mathrm{hr}\end{array}$ & $\begin{array}{c}\text { Emission } \\
\text { constrained } \\
\text { fuel cost } \\
\text { Rs/hr }\end{array}$ & $\begin{array}{c}\text { Execution } \\
\text { Time in } \\
\text { Seconds }\end{array}$ \\
\hline 400 & 101.56 & 154.56 & 143.88 & 20560.89 & 198.53 & 30673.63 & 0.285 \\
\hline 500 & 123.76 & 186.89 & 189.35 & 25435.34 & 319.54 & 41256.95 & 0.179 \\
\hline 600 & 152.53 & 227.45 & 220.02 & 30587.93 & 458.4 & 51634.83 & 0.201 \\
\hline 700 & 185.42 & 275.85 & 238.73 & 36788.52 & 645.95 & 67943.63 & 0.221 \\
\hline
\end{tabular}

Table 3: Cost Coefficients and Emission Coefficients of Six Generator Test System Fuel cost coefficients $\mathrm{CO}_{2}$ emission coefficients

\begin{tabular}{rrrrrr}
\hline 0.002035 & 8.43205 & 85.6348 & 0.2651 & -61.0195 & 5080.148 \\
0.003866 & 6.41031 & 303.778 & 0.1401 & -29.9522 & 3824.77 \\
0.002182 & 7.4289 & 847.148 & 0.1059 & -9.55279 & 1342.851 \\
0.001345 & 8.30154 & 274.224 & 0.1064 & -12.7362 & 1819.625 \\
0.002182 & 7.4289 & 847.148 & 0.1059 & -9.55279 & 1342.851 \\
0.005936 & 6.91559 & 202.026 & 0.4031 & -121.981 & 11381.070 \\
\hline
\end{tabular}

Table4: Fuel cost, CO2, Emission Constrained Fuel Cost (ECFC) and Power Loss of Six Generator System for Various Load Demand

\begin{tabular}{ccccccc}
\hline & $\begin{array}{c}\mathrm{Pd}=1800 \\
\mathrm{MW}\end{array}$ & $\begin{array}{c}\mathrm{Pd}=1900 \\
\mathrm{MW}\end{array}$ & $\begin{array}{c}\mathrm{Pd}=2000 \\
\mathrm{MW}\end{array}$ & $\begin{array}{c}\mathrm{Pd}=2100 \\
\mathrm{MW}\end{array}$ & $\begin{array}{c}\mathrm{Pd}=2200 \\
\mathrm{MW}\end{array}$ & $\begin{array}{c}\mathrm{Pd}=2300 \\
\mathrm{MW}\end{array}$ \\
\hline $\mathrm{P1}$ & 241.095 & 251.441 & 263.19 & 276.6688 & 295.7223 & 303.5778
\end{tabular}




\begin{tabular}{ccccccc} 
P2 & 320.674 & 336.756 & 354.73 & 375.0587 & 400.000 & 403.5778 \\
P3 & 371.479 & 398.294 & 428.56 & 463.1344 & 512.4469 & 603.5778 \\
P4 & 363.782 & 387.674 & 400.00 & 400.00 & 400.000 & 403.5778 \\
P5 & 380.301 & 408.791 & 441.33 & 479.0396 & 500.000 & 503.5778 \\
P6 & 230.218 & 236.554 & 243.86 & 250.000 & 250.000 & 253.5778 \\
Fuel cost RS/hr & 18470.6 & 19501 & 20544 & 21600.4624 & 22689.7301 & 23801.94 \\
$\mathrm{CO}_{2}$ Emission in & & & & & & \\
$\mathrm{Kg} / \mathrm{hr}$ & 55776.6 & 63560.6 & 72030 & 81330.7993 & 91618.3172 & 103481.9 \\
ECFC Rs/hr & 55616.3 & 61830.6 & 68514 & 75764.6127 & 83705.0939 & 92718.13 \\
\hline
\end{tabular}

\section{CONCLUSION}

An Evolutionary Programming Technique has been developed for the combined economic emission thermal power dispatch to reduce the fuel cost and emission of the plant to prevent the global warming. This Technique was implemented and tested on three and six generator system. EP is an efficient tool for the economic scheduling for generating units with the given generator constraints. The quality of the solutions generated by the EP offers an excellent approach to solve the economic thermal power dispatch problem. The solution is analytic in nature with high accuracy and less computational time and it is used for any online application. The performance and applicability of the proposed method are shown.

\section{ACKNOWLEDGMENTS}

The authors gratefully acknowledge the authorities of St.Joseph college of Engineering and Technology,

Dar Es

Salaam, Tanzania for the facilities offered to carry out this work.

\section{REFERENCES}

[1] Liladhur G. Sewothul, Robert T.F. Ah King and Harry C.S. Rughooputh, "Genetic algorithms for economic dispatch with valve point effect", Proceedings of the IEEE, International conference on Networking, Sensing \& Control, pp.1358-1362, March 2004.

[2] M. Basu, "An interactive fuzzy satisfying-based simulated annealing techniques for economic emission load dispatch with nonsmooth fuel cost and emission level functions", Electric Power Components and Systems, vol.32, no.2, pp.163-173, 2004.

[3] C.E. Lin and G.L. Viviani, "Hierarchical economic dispatch for piecewise quadratic cost functions," IEEE Trans. Power Apparatus Syst., vol. PAS-103, pp. 1170-1175, June 1984

[4] Z.X. Liang and J.D. Glover, "Azoom feature for a dynamic programming solution to economic dispatch including transmission losses," Trans. Power Syst., vol. 7, pp. 544550, May 1992.

[5] E. H. Chowdhury, Saifur Rahrnan. 1990. A Review of Recent Advances in Economic Dispatch. IEEE Trans. on Power Syst. 5(Nov.): 1248-1259.

[6] Palanichamy C., Srikrishna K. 1991. Economic thermal power dispatch with emission constraint. J. Institution of Engineers (India). 72(April): 11-18.

[7] K. Y. Lee, A. S. Yome, and J. H. Park, "Adaptive Hopfield networks for economic load dispatch," IEEE Trans. Power Syst., vol. 13, pp. 519-526, May 1998.

[8] A.H. Mantawy, Y.L Abdel-Magid, and S.Z. Selim,"A new genetic-based simple tabu search algorithm for unit commitment problem," Electr.power syst. Res. 49,pp. 7178,1999 .

[9] Konash, O.El-Sharakawi, M, "Economic Dispatch using Particle Swarm Optimization for combined cycle generators" Power Systems Conference and Exposition, 2009. PSCE IEEE/PES Volume, Issue,15-18 March 2009 Page(s):1-9.

[10] K.P.Wong and C.C.Fung, Simulated Annealing based Economic Load Dispatch, IEEE proceedings on Generation, Transmission and Distribution-C, Vol.140,No.6, Nov 1993, pp509-513.

[11] K. P. Wong and J. Yuryevich, "Evolutionaryprogramming-based algorithm for environmentallyconstrained economic dispatch," IEEE Trans. Power Syst., vol. 13, pp. 301-306, May 1998.

[12] I. J. Nagrat, P. Kothari. 1989. Modern Power System Analysis. Tata McGraw-Hill Publishing Company Ltd., New Delhi, India.

[13] Wood A.J and Woolenberg BF (1996), “ Power Generation and Control", John willey and sons, New York.

[14] D.P. Kothari and J.S.Dhillon (2004), “ Power System Optimization", Prentice - Hall of India, New Delhi. 